\title{
Fractional Crystallization Feed Envelope
}

\author{
D. L. Herting \\ CH2M HILL Hanford Group, Inc. \\ Richland, WA 99352
}

U.S. Department of Energy Contract DE-AC27-99RL14047

$\begin{array}{lll}\text { EDT/ECN: } & \text { DRF } & \text { UC: } \\ \text { Cost Center: } & 74 A 10 & \text { Charge Code: } \\ \text { B\&R Code: } & & \text { Total Pages: } 27\end{array}$

Key Words: fractional, crystallization, feed, envelope, limits, evaporation, tests, process, vacuum, saturated, brine, solution, filter, cake, variables, aluminate, phosphate, sulfate, hydroxide, EDTA, HEDTA, NTA, thermodynamic, modeling, slurry, ICP, boildown, responses, bumping, frothing, filtrate, filtration, crystals, chromate, decontamination factor, sodium, recovery, saltcake

Abstract: Laboratory work was completed on a set of evaporation tests designed to establish a feed envelope for the fractional crystallization process. The feed envelope defines chemical concentration limits within which the process can be operated successfully. All 38 nuns in the half-factorial design matrix were completed successfully, based on the qualitative definition of success. There is no feed composition likely to be derived from saltcake dissolution that would cause the fractional crystallization process to not meet acceptable performance requirements. However, some compositions clearly would provide more successful operation than other compositions.

TRADEMARK DISCLAIMER. Reference herein to any specific commercial product, process, or service by trade name, trademark, manufacturer, or otherwise, does not necessarily constitute or imply its endorsement, recommendation, or favoring by the United States Government or any agency thereof or its contractors or subcontractors.

Printed in the United States of America. To obtain coples of this document, contact: Document Control Services, P.O. Box 950, Mailstop H6-08, Richland WA 99352, Phone (509) 372-2420; Fax (509) 376-4989.

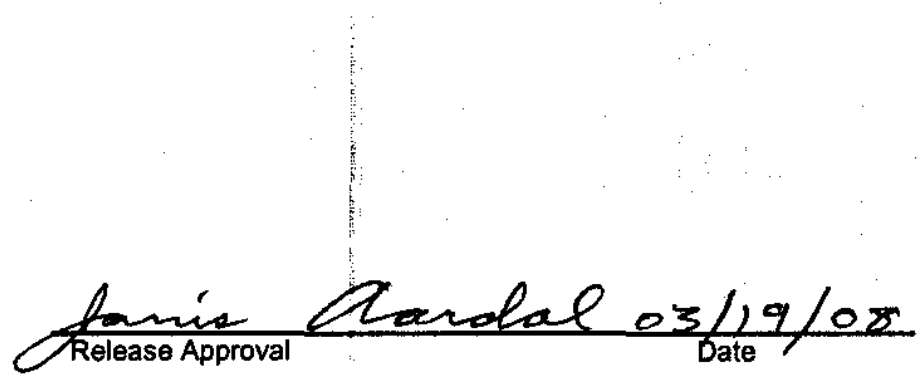

Approved For Public Release

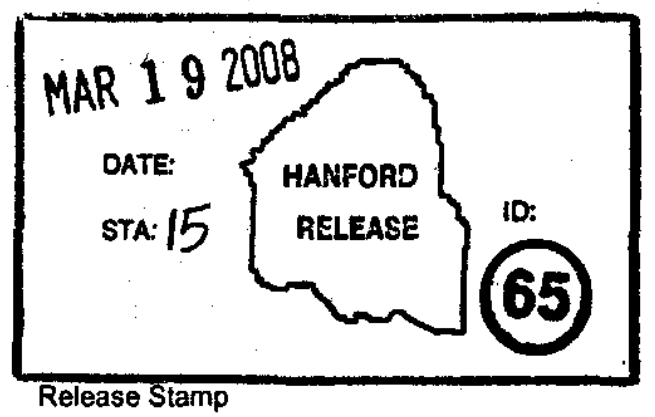

Release Stamp 


\title{
FRACTIONAL CRYSTALLIZATION FEED ENVELOPE
}

\author{
D. L. Herting \\ CH2M HILL Hanford Group, Inc.
}

Date Published

March 2008

\section{CH2MHILL \\ Hanford Group, Inc.}

Prepared for the U.S. Department of Energy

Office of River Protection

Contract No. DE-AC27-99RL14047 


\section{TABLE OF CONTENTS}

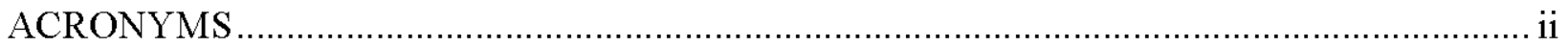

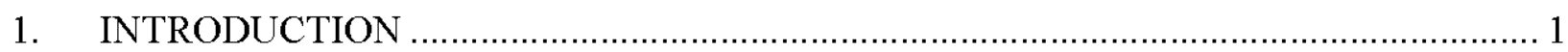

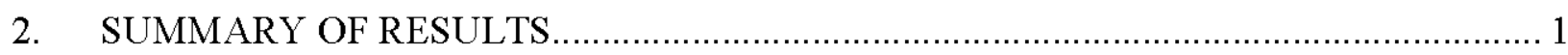

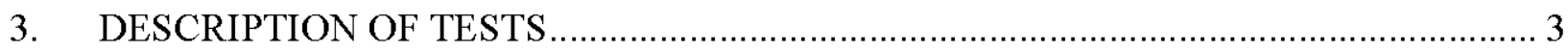

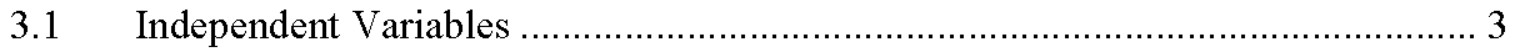

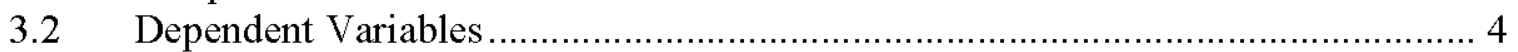

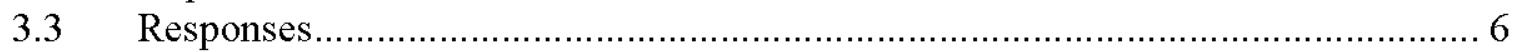

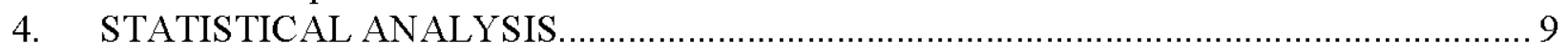

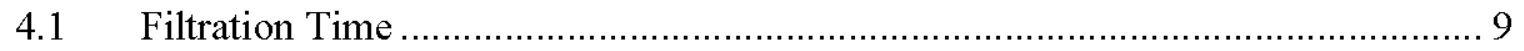

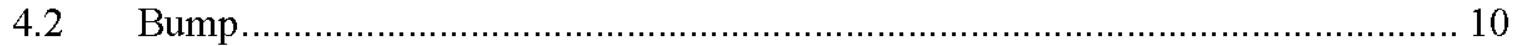

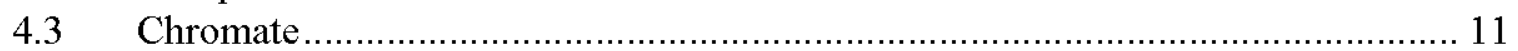

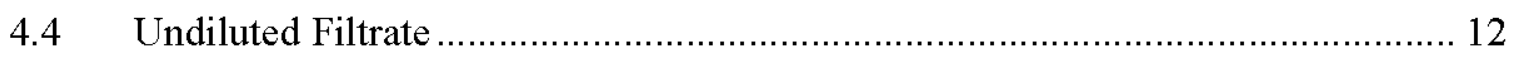

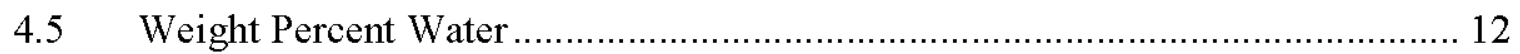

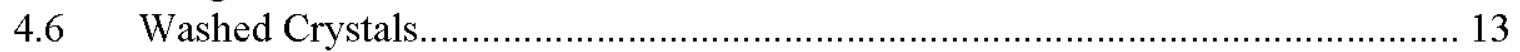

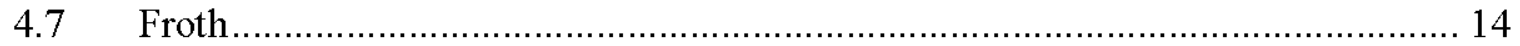

5. DECONTAMINATION FACTORS AND SODIUM RECOVERY ............................. 14

5.1 Decontamination Factors ……............................................................. 14

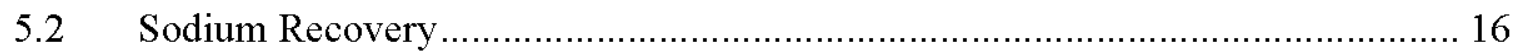

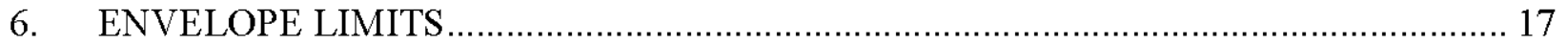

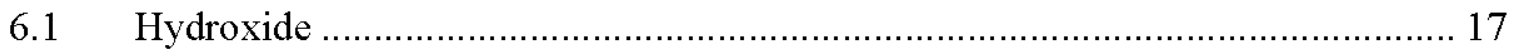

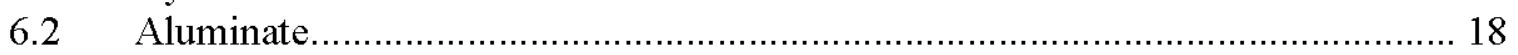

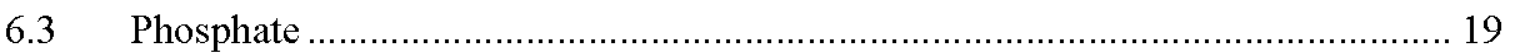

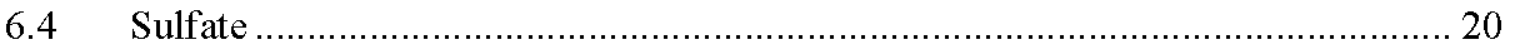

6.5 Ethylenediaminetetraacetic Acid, Tetrasodium Salt........................................ 20

6.6 Nitrilotriacetic Acid, Trisodium Salt .......................................................... 21

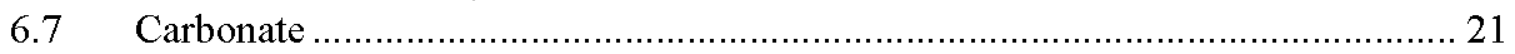

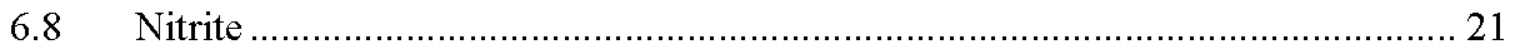

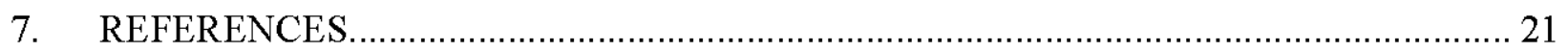

\section{LIST OF FIGURES}

Figure 1. Hydroxide Effect on Filtration Time.......................................................... 10

Figure 2. Lack of Correlation Between $\% \mathrm{H}_{2} \mathrm{O}$ and $\mathrm{Cr}$ in Washed Solids. .............................. 13

Figure 3. Correlation Between Mass of Washed Crystals and Nitrate Molarity...................... 14

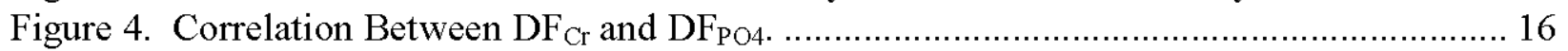

Figure 5. Correlation Between Percent Yield and the Mass of Unwashed Crystals.................. 17

\section{LIST OF TABLES}

Table 1. Proposed Feed Envelope for the Fractional Crystallization Process. ........................... 2

Table 2. Analyte:Na Mole Ratios for Independent Variables................................................. 3

Table 3. Concentrations in Molarity for Half-Factorial Matrix Feed Solutions

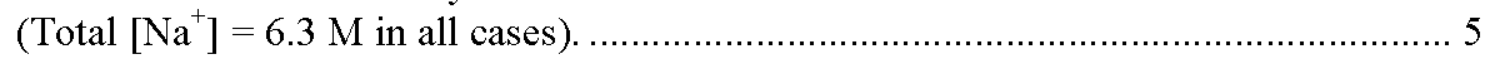

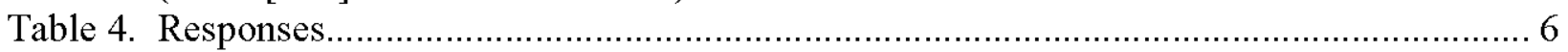


Table 5. Concentrations of Metals by Inductively Coupled Plasma Spectroscopy in Washed

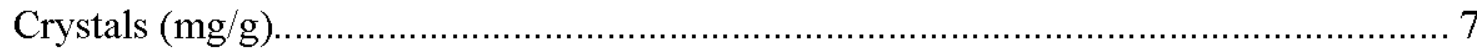

Table 6. Calculated $\mathrm{Cr}(\mathrm{VI})$ Concentration at Different Variable Settings [sorted by calculated

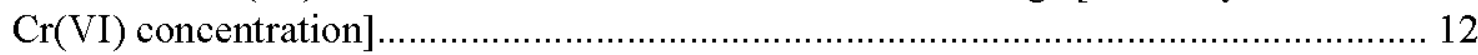

Table 7. Decontamination Factors and \%Yield. ................................................................ 15

\section{ACRONYMS}

BBI

DF

EDTA

Georgia Tech

HEDTA

ICP

ND

NTA best-basis inventory

decontamination factor

ethylenediaminetetraacetic acid, tetrasodium salt

Georgia Institute of Technology

$\mathrm{N}$-(2-hydroxyethyl)ethylenediaminetriacetic acid, trisodium salt inductively coupled plasma spectroscopy

not determined

nitrilotriacetic acid, trisodium salt 


\section{INTRODUCTION}

Laboratory work was completed on a set of evaporation tests designed to establish a feed envelope for the fractional crystallization process, as outlined in the test plan (Interoffice memo 7S110-DLH-07-122, "Test Plan for Envelope Limit Factorial Design Test"). The feed envelope defines chemical concentration limits within which the process can be operated successfully. Qualitatively, successful operation is defined as

a. The solution can be evaporated under vacuum without excessive frothing or bumping (see Section 3.3 for definitions).

b. The slurry resulting from the evaporation can be separated effectively into solid and liquid streams, resulting in adequate decontamination of the crystals.

c. The amount of sodium in the recovered crystals represents a reasonable percentage of the total sodium in the feed solution.

The laboratory program was based on a half-factorial design matrix with six independent variables at two levels each, resulting in 32 runs (half of $2^{6}$ ), plus six center points for a total of 38 runs. Each run consisted of vacuum evaporation of a simulated waste solution, filtration of the slurry resulting from the evaporation, washing of the filter cake with a saturated brine solution, and collection and analysis of the washed filter cake. Results were subjected to a statistical analysis of the data (PNNL-17380, Analysis of Results from the Design Envelope Limit Experiment).

The independent variables were selected based on their potential for having an impact on the process outcome. The six variables selected were aluminate, phosphate, sulfate, hydroxide, ethylenediaminetetraacetic acid, tetrasodium salt/N-(2-hydroxyethyl)ethylenediaminetriacetic acid, trisodium salt (EDTA/HEDTA) and nitrilotriacetic acid, trisodium salt (NTA). Section 3.1 provides additional discussion on the selection of these independent variables.

\section{SUMMARY OF RESULTS}

All 38 runs in the half-factorial design matrix were completed successfully, based on the qualitative definition of success defined in Section 1. In other words, there is no feed composition likely to be derived from saltcake dissolution that would cause the fractional crystallization process to not meet acceptable performance requirements. However, some compositions clearly would provide more successful operation than other compositions.

Table 1 shows the proposed feed envelope for the fractional crystallization process. There are no lower concentration limits for the process, i.e., the concentration of any component could be set to zero without causing process failure. The upper concentration limit for each analyte is shown in the table in two ways, analyte:Na mole ratio and analyte molarity. The analyte:Na mole ratio is more versatile in that it may be calculated for any feed solution at any concentration, but these values are not "intuitive." Therefore, concentration limits are also given in molarity of each analyte for a solution normalized to $5 \mathrm{M}$ total sodium. 
Three previous feed envelope evaluations were made, one based on thermodynamic modeling (RPP-34455, Hanford Medium/Low Curie Waste Pretreatment Alternatives Project - Subtask 2.1 and Subtask 2.2) and two based on laboratory testing (RPP-RPT-34136, Hanford Medium/Low Curie Waste Pretreatment Alternatives Project-Phase II, Subtask 2.5 and Subtask 2.6, and RPP-RPT-35261, Fractional Crystallization Laboratory Tests with Simulated Tank Waste). Results of the prior evaluations are incorporated into the values entered in Table 1, as discussed in Section 5.

Table 1. Proposed Feed Envelope for the Fractional Crystallization Process.

\begin{tabular}{|c|c|c|c|}
\hline \multirow[b]{2}{*}{ Analyte } & \multicolumn{2}{|c|}{$\begin{array}{l}\text { Maximum Concentration } \\
\text { (Envelope Limit) }\end{array}$} & \multirow[b]{2}{*}{ Consequence of Exceeding Maximum Concentration Limit } \\
\hline & $\begin{array}{l}\text { Analyte:Na } \\
\text { Mole Ratio }\end{array}$ & $\begin{array}{l}\text { Molarity } \\
\text { at } 5 \text { M Na }\end{array}$ & \\
\hline $\mathrm{OH}$ & $(0.42-\mathrm{Al})^{\mathrm{a}}$ & $(2.1-\mathrm{Al})^{\mathrm{a}}$ & Sodium yield drops $<50 \%$ \\
\hline $\mathrm{CO}_{3}$ & 0.50 & 2.5 & None; limited only by solubility \\
\hline $\mathrm{Al}$ & 0.15 & 0.75 & High viscosity, poor separation, low yield \\
\hline $\mathrm{CrO}_{4}$ & $\mathrm{ND}^{\mathrm{b}}$ & $\mathrm{ND}$ & Unlikely to cause problems \\
\hline $\mathrm{K}$ & $\mathrm{ND}$ & ND & Unlikely to cause problems \\
\hline $\mathrm{PO}_{4}$ & 0.06 & 0.30 & $\begin{array}{l}\text { Increased risk of transfer pipe plugging; excessive bumping in } \\
\text { evaporator }\end{array}$ \\
\hline $\mathrm{SO}_{4}$ & 0.06 & 0.30 & None \\
\hline F & $\mathrm{ND}$ & ND & Higher concentrations are beneficial \\
\hline $\mathrm{Cl}$ & $\mathrm{ND}$ & ND & Unlikely to cause problems \\
\hline $\mathrm{NO}_{2}$ & 0.20 & 1.0 & Sodium yield drops $<50 \%$ \\
\hline $\mathrm{NO}_{3}$ & 1.00 & 5.0 & None \\
\hline $\begin{array}{l}\mathrm{C}_{2} \mathrm{O}_{4} \\
\text { (oxalate) }\end{array}$ & $\mathrm{ND}$ & $\mathrm{ND}$ & Limited only by solubility \\
\hline EDTA $^{\mathrm{c}}$ & 0.0014 & 0.007 & Bumping/frothing, poor separation \\
\hline HEDTA $^{\mathrm{d}}$ & 0.0014 & 0.007 & Bumping/frothing, poor separation \\
\hline NTA $^{\mathrm{e}}$ & 0.00025 & 0.0013 & Bumping/frothing, poor separation \\
\hline
\end{tabular}

${ }^{a} \mathrm{OH}$ limit depends on $\mathrm{Al}$ concentration; e.g., if $\mathrm{Al}: \mathrm{Na}$ mole ratio $=0.10$, then $\mathrm{OH}: \mathrm{Na}$ limit is $0.42-0.10=0.32$; alternatively, if $\mathrm{Al}$ concentration $=0.5 \mathrm{M}$ (at $5 \mathrm{M} \mathrm{Na}$ ), then the $\mathrm{OH}$ limit is $2.1-0.5=1.6 \mathrm{M}$.

${ }^{\mathrm{b}} \mathrm{ND} \quad=$ not determined

${ }^{c}$ EDTA = ethylenediaminetetraacetic acid, tetrasodium salt

${ }^{\mathrm{d}}$ HEDTA $=\mathrm{N}$-(2-hydroxyethyl)ethylenediaminetriacetic acid, trisodium salt

${ }^{\mathrm{e}} \mathrm{NTA}=$ nitrilotriacetic acid, trisodium salt

The concentration limits in Table 1 are approximate, and are not rigid, but serve as a preliminary guideline for feed evaluation. Both thermodynamic modeling and the results of the half-factorial test clearly show that component interactions play an important role in determining waste behaviors. For example, filtration time, which is one measure of the efficiency of solid/liquid separation, increases with increasing phosphate concentration but only when the sulfate concentration is low. The effect reverses at high sulfate concentration. This is one example of a significant interaction, several of which were revealed by the half-factorial test results.

Therefore, the attempt to describe a feed envelope by listing the maximum concentration of each analyte in the feed (which is exactly what is attempted in Table 1) is simplistic and the values must be considered approximations. 


\section{DESCRIPTION OF TESTS}

The test matrix was based on a half-factorial design with six independent variables at two levels each [High $(+1)$ and Low (-1)] plus six center points $(0)$, for a total of 38 runs. Each run consisted of a vacuum evaporation (called a boildown) of the prescribed feed solution at a constant temperature of $60^{\circ} \mathrm{C}$. The planned end point for each boildown was the point at which the slurry contained $30 \%$ solids. With no way to measure the percent solids in the slurry directly, the end point was chosen in practice by comparing the apparent slurry density against prior baseline or practice tests using "SST Early" feed.

When the boildown end point was reached, the slurry was poured into a temperature-controlled vacuum filter (medium glass frit filter with water jacket). The filter cake was washed five times with small portions of a saturated brine solution. (In a few cases, the wash was performed four times with a slightly larger volume of wash liquid for each wash.) The washed filter cake was collected and analyzed for (a) percent water $\left(\% \mathrm{H}_{2} \mathrm{O}\right)$ by oven drying and (b) elemental concentrations (Al, Cr, P, Na) by inductively coupled plasma spectroscopy (ICP). The ICP analysis was not a requirement included in the test plan (7S110-DLH-07-122) but was added after consultation with the customer.

\subsection{INDEPENDENT VARIABLES}

Six independent variables were selected based on their potential for having an impact on the process outcome. The six variables and their settings are shown in Table 2 . The low (-1) value for each variable was set equal to the concentration in the simulated SST Early feed solution used in prior tests (RPP-RPT-35261, RPP-RPT-34136, and others), except for the levels of EDTA/HEDTA and NTA, which were absent in SST Early. For those variables, the low value was set equal to one-half of the high value.

Table 2. Analyte:Na Mole Ratios for Independent Variables.

\begin{tabular}{|c|c|c|c|}
\hline Variable & Low (-1) & Medium (0) & High (+1) \\
\hline $\mathrm{Al}$ & 0.046 & 0.098 & 0.150 \\
\hline $\mathrm{PO}_{4}$ & 0.007 & 0.0335 & 0.060 \\
\hline $\mathrm{SO}_{4}$ & 0.022 & 0.031 & 0.040 \\
\hline $\mathrm{OH}$ & 0.098 & 0.204 & 0.310 \\
\hline EDTA/HEDTA & 0.0014 & 0.0021 & 0.0027 \\
\hline NTA & 0.000125 & 0.00019 & 0.00025 \\
\hline
\end{tabular}

${ }^{*}$ Sum of EDTA and HEDTA concentrations, with equi-molar amounts of each.

The high $(+1)$ values for the inorganic variables were derived from the best-basis inventory (BBI) information available at the time of the study. The values in Table 2 represent the practical upper limits that would be observed in dissolved saltcake retrieved from single-shell tanks in the 200 West Area. For the organic variables (EDTA/HEDTA and NTA), the high values were set at one-half of the value that resulted in processing problems in a prior laboratory study (RPP-RPT-34136) at the Georgia Institute of Technology (Georgia Tech).

Medium (0) values in all cases were set at the midpoint between the high and low values. 


\subsection{DEPENDENT VARIABLES}

The variable held constant in all 38 runs was the total $\mathrm{Na}$ concentration, which was set at the SST Early value of $6.3 \mathrm{M}$. To increase the Analyte:Na ratio of one or more of the independent variables in Table 2, the laws of chemistry require that the Analyte:Na ratio of one or more of the remaining solution components (the dependent variables) must decrease. Several alternative methods were evaluated for maintaining the charge balance. The method selected was to decrease all of the dependent variable concentrations in proportion to their concentrations in SST Early feed. The dependent variables were $\mathrm{Na}_{2} \mathrm{CO}_{3}, \mathrm{NaCl}, \mathrm{Na}_{2} \mathrm{CrO}_{4}, \mathrm{NaF}, \mathrm{KNO}_{3}, \mathrm{NaNO}_{2}$, $\mathrm{NaNO}_{3}$, and $\mathrm{Na}_{3} \mathrm{C}_{6} \mathrm{H}_{5} \mathrm{O}_{7}$ (sodium citrate). Concentrations of all the solution components are shown in molarity in Table 3. 
Table 3. Concentrations in Molarity for Half-Factorial Matrix Feed Solutions (Total $\left[\mathrm{Na}^{+}\right]=6.3 \mathrm{M}$ in all cases).

\begin{tabular}{|c|c|c|c|c|c|c|c|c|c|c|c|c|c|c|c|}
\hline \multirow[b]{2}{*}{ Test } & \multicolumn{7}{|c|}{ Independent Variables } & \multicolumn{8}{|c|}{ Dependent Variables } \\
\hline & $\mathrm{NaAl}(\mathrm{OH})_{4}$ & $\mathrm{Na}_{3} \mathrm{PO}_{4}$ & $\mathrm{Na}_{2} \mathrm{SO}_{4}$ & $\mathrm{NaOH}$ & EDTA & HEDTA & NTA & $\mathrm{Na}_{2} \mathrm{CO}_{3}$ & $\mathrm{NaCl}$ & $\mathrm{Na}_{2} \mathrm{CrO}_{4}$ & $\mathrm{NaF}$ & $\mathrm{KNO}_{3}$ & $\mathrm{NaNO}_{2}$ & $\mathrm{NaNO}_{3}$ & $\mathrm{Na}_{3} \mathrm{C}_{6} \mathrm{H}_{5} \mathrm{O}_{7}$ \\
\hline 1 & 0.29 & 0.04 & 0.14 & 0.61 & 0.004 & 0.004 & 0.001 & 0.58 & 0.07 & 0.018 & 0.012 & 0.018 & 0.49 & 3.13 & 0.012 \\
\hline 2 & 0.94 & 0.04 & 0.14 & 0.61 & 0.004 & 0.004 & 0.002 & 0.51 & 0.06 & 0.016 & 0.010 & 0.016 & 0.43 & 2.72 & 0.010 \\
\hline 3 & 0.28 & 0.37 & 0.14 & 0.61 & 0.004 & 0.004 & 0.002 & 0.46 & 0.06 & 0.014 & 0.009 & 0.014 & 0.39 & 2.47 & 0.009 \\
\hline 4 & 0.93 & 0.37 & 0.14 & 0.61 & 0.004 & 0.004 & 0.001 & 0.38 & 0.05 & 0.012 & 0.008 & 0.012 & 0.32 & 2.06 & 0.008 \\
\hline 5 & 0.29 & 0.04 & 0.25 & 0.61 & 0.004 & 0.004 & 0.002 & 0.56 & 0.07 & 0.017 & 0.011 & 0.017 & 0.47 & 2.99 & 0.011 \\
\hline 6 & 0.94 & 0.04 & 0.25 & 0.61 & 0.004 & 0.004 & 0.001 & 0.48 & 0.06 & 0.015 & 0.010 & 0.015 & 0.41 & 2.58 & 0.010 \\
\hline 7 & 0.28 & 0.37 & 0.25 & 0.61 & 0.004 & 0.004 & 0.001 & 0.43 & 0.05 & 0.013 & 0.009 & 0.013 & 0.37 & 2.33 & 0.009 \\
\hline 8 & 0.93 & 0.37 & 0.25 & 0.61 & 0.004 & 0.004 & 0.002 & 0.36 & 0.04 & 0.011 & 0.007 & 0.011 & 0.30 & 1.92 & 0.007 \\
\hline 9 & 0.29 & 0.04 & 0.14 & 1.94 & 0.004 & 0.004 & 0.002 & 0.43 & 0.05 & 0.013 & 0.009 & 0.013 & 0.36 & 2.29 & 0.009 \\
\hline 10 & 0.94 & 0.04 & 0.14 & 1.94 & 0.004 & 0.004 & 0.001 & 0.35 & 0.04 & 0.011 & 0.007 & 0.011 & 0.30 & 1.88 & 0.007 \\
\hline 11 & 0.28 & 0.37 & 0.14 & 1.92 & 0.004 & 0.004 & 0.001 & 0.31 & 0.04 & 0.009 & 0.006 & 0.009 & 0.26 & 1.64 & 0.006 \\
\hline 12 & 0.93 & 0.37 & 0.14 & 1.92 & 0.004 & 0.004 & 0.002 & 0.23 & 0.03 & 0.007 & 0.005 & 0.007 & 0.19 & 1.23 & 0.005 \\
\hline 13 & 0.94 & 0.04 & 0.25 & 0.61 & 0.004 & 0.004 & 0.001 & 0.48 & 0.06 & 0.015 & 0.010 & 0.015 & 0.41 & 2.58 & 0.010 \\
\hline 14 & 0.94 & 0.04 & 0.25 & 1.94 & 0.004 & 0.004 & 0.002 & 0.32 & 0.04 & 0.010 & 0.007 & 0.010 & 0.27 & 1.73 & 0.007 \\
\hline 15 & 0.28 & 0.37 & 0.25 & 1.92 & 0.004 & 0.004 & 0.002 & 0.28 & 0.03 & 0.009 & 0.006 & 0.009 & 0.24 & 1.49 & 0.006 \\
\hline 16 & 0.93 & 0.37 & 0.25 & 1.92 & 0.004 & 0.004 & 0.001 & 0.20 & 0.03 & 0.006 & 0.004 & 0.006 & 0.17 & 1.08 & 0.004 \\
\hline 17 & 0.29 & 0.04 & 0.14 & 0.61 & 0.009 & 0.009 & 0.002 & 0.58 & 0.07 & 0.018 & 0.012 & 0.018 & 0.49 & 3.11 & 0.012 \\
\hline 18 & 0.94 & 0.04 & 0.14 & 0.61 & 0.009 & 0.009 & 0.001 & 0.50 & 0.06 & 0.016 & 0.010 & 0.016 & 0.43 & 2.70 & 0.010 \\
\hline 19 & 0.28 & 0.37 & 0.14 & 0.61 & 0.008 & 0.008 & 0.001 & 0.46 & 0.06 & 0.014 & 0.009 & 0.014 & 0.39 & 2.45 & 0.009 \\
\hline 20 & 0.93 & 0.37 & 0.14 & 0.61 & 0.009 & 0.009 & 0.002 & 0.38 & 0.05 & 0.012 & 0.008 & 0.012 & 0.32 & 2.04 & 0.008 \\
\hline 21 & 0.29 & 0.04 & 0.25 & 0.61 & 0.009 & 0.009 & 0.001 & 0.55 & 0.07 & 0.017 & 0.011 & 0.017 & 0.47 & 2.97 & 0.011 \\
\hline 22 & 0.94 & 0.04 & 0.25 & 0.61 & 0.009 & 0.009 & 0.002 & 0.48 & 0.06 & 0.015 & 0.010 & 0.015 & 0.40 & 2.56 & 0.010 \\
\hline 23 & 0.28 & 0.37 & 0.25 & 0.61 & 0.008 & 0.008 & 0.002 & 0.43 & 0.05 & 0.013 & 0.009 & 0.013 & 0.36 & 2.31 & 0.009 \\
\hline 24 & 0.93 & 0.37 & 0.25 & 0.61 & 0.009 & 0.009 & 0.001 & 0.35 & 0.04 & 0.011 & 0.007 & 0.011 & 0.30 & 1.90 & 0.007 \\
\hline 25 & 0.29 & 0.04 & 0.14 & 1.94 & 0.009 & 0.009 & 0.001 & 0.42 & 0.05 & 0.013 & 0.009 & 0.013 & 0.36 & 2.27 & 0.009 \\
\hline 26 & 0.94 & 0.04 & 0.14 & 1.94 & 0.009 & 0.009 & 0.002 & 0.35 & 0.04 & 0.011 & 0.007 & 0.011 & 0.29 & 1.86 & 0.007 \\
\hline 27 & 0.28 & 0.37 & 0.14 & 1.92 & 0.009 & 0.009 & 0.002 & 0.30 & 0.04 & 0.009 & 0.006 & 0.009 & 0.25 & 1.62 & 0.006 \\
\hline 28 & 0.93 & 0.37 & 0.14 & 1.92 & 0.009 & 0.009 & 0.001 & 0.23 & 0.03 & 0.007 & 0.005 & 0.007 & 0.19 & 1.21 & 0.005 \\
\hline 29 & 0.29 & 0.04 & 0.25 & 1.94 & 0.009 & 0.009 & 0.002 & 0.40 & 0.05 & 0.012 & 0.008 & 0.012 & 0.34 & 2.13 & 0.008 \\
\hline 30 & 0.94 & 0.04 & 0.25 & 1.94 & 0.009 & 0.009 & 0.001 & 0.32 & 0.04 & 0.010 & 0.007 & 0.010 & 0.27 & 1.71 & 0.007 \\
\hline 31 & 0.28 & 0.37 & 0.25 & 1.92 & 0.009 & 0.009 & 0.001 & 0.28 & 0.03 & 0.009 & 0.006 & 0.009 & 0.23 & 1.48 & 0.006 \\
\hline 32 & 0.93 & 0.37 & 0.25 & 1.92 & 0.009 & 0.009 & 0.002 & 0.20 & 0.02 & 0.006 & 0.004 & 0.006 & 0.17 & 1.06 & 0.004 \\
\hline 33 & 0.61 & 0.21 & 0.19 & 1.27 & 0.007 & 0.007 & 0.001 & 0.39 & 0.05 & 0.012 & 0.008 & 0.012 & 0.33 & 2.09 & 0.008 \\
\hline 34 & 0.61 & 0.21 & 0.19 & 1.27 & 0.007 & 0.007 & 0.001 & 0.39 & 0.05 & 0.012 & 0.008 & 0.012 & 0.33 & 2.09 & 0.008 \\
\hline 35 & 0.61 & 0.21 & 0.19 & 1.27 & 0.007 & 0.007 & 0.001 & 0.39 & 0.05 & 0.012 & 0.008 & 0.012 & 0.33 & 2.09 & 0.008 \\
\hline 36 & 0.61 & 0.21 & 0.19 & 1.27 & 0.007 & 0.007 & 0.001 & 0.39 & 0.05 & 0.012 & 0.008 & 0.012 & 0.33 & 2.09 & 0.008 \\
\hline 37 & 0.61 & 0.21 & 0.19 & 1.27 & 0.007 & 0.007 & 0.001 & 0.39 & 0.05 & 0.012 & 0.008 & 0.012 & 0.33 & 2.09 & 0.008 \\
\hline 38 & 0.61 & 0.21 & 0.19 & 1.27 & 0.007 & 0.007 & 0.001 & 0.39 & 0.05 & 0.012 & 0.008 & 0.012 & 0.33 & 2.09 & 0.008 \\
\hline
\end{tabular}




\subsection{RESPONSES}

Several "responses," or data measurements, were recorded for each test. Results are shown in Tables 4 and 5. A description of each response follows.

Table 4. Responses.

\begin{tabular}{|c|c|c|c|c|c|c|c|c|}
\hline Test & Levels $^{\mathrm{a}}$ & Froth $^{b}$ & Bump ${ }^{b}$ & $\begin{array}{c}\text { Filtration } \\
\text { Time (min) }\end{array}$ & $\begin{array}{l}\text { Filtrate } \\
\text { (g) }\end{array}$ & $\begin{array}{l}\text { Unwashed } \\
\text { Crystals (g) }\end{array}$ & $\begin{array}{c}\text { Washed } \\
\text { Crystals } \\
\text { (g) }\end{array}$ & $\% \mathrm{H}_{2} \mathrm{O}$ \\
\hline 1 & $\cdots$ & 0 & 2 & 2.62 & 77.66 & 77.60 & 66.41 & 16.77 \\
\hline 2 & $+\ldots-\ldots+$ & 1 & 2 & 1.48 & 66.65 & 88.44 & 70.29 & 16.82 \\
\hline 3 & $-+\ldots+$ & 1 & 1 & 2.78 & 72.82 & 83.02 & 67.86 & 19.43 \\
\hline 4 & $++\ldots-\cdots$ & 1 & 1 & 3.83 & 88.91 & 75.90 & 61.86 & 21.01 \\
\hline 5 & --+--+ & 2 & 2 & 2.30 & 68.66 & 89.94 & 65.19 & 13.69 \\
\hline 6 & +-+--- & 1 & 1 & 2.33 & 81.53 & 80.77 & 64.12 & 15.70 \\
\hline 7 & $-++\ldots$ & 1 & 0 & 1.57 & 83.30 & 75.95 & 57.01 & 19.53 \\
\hline 8 & $+++\ldots+$ & 1 & 0 & 2.32 & 108.19 & 63.36 & 54.41 & 20.89 \\
\hline 9 & --++-+ & 2 & 1 & 1.80 & 87.85 & 67.57 & 58.47 & 17.02 \\
\hline 10 & $+\ldots+--$ & 2 & 1 & 1.50 & 119.69 & 43.29 & 45.71 & 20.30 \\
\hline 11 & -+-+-- & 1 & 1 & 1.67 & 95.22 & 61.58 & 47.54 & 22.94 \\
\hline 12 & ++-+-+ & 0 & 0 & 1.23 & 127.53 & 36.78 & 29.30 & 21.24 \\
\hline 13 & $+-+\ldots$ & 1 & 1 & 2.47 & 99.66 & 65.21 & 59.22 & 14.96 \\
\hline 14 & +-++-+ & 1 & 1 & 1.18 & 118.52 & 40.13 & 42.17 & 15.79 \\
\hline 15 & -+++-+ & 1 & 0 & 1.10 & 106.53 & 44.01 & 36.98 & 21.81 \\
\hline 16 & ++++-- & 2 & 1 & 1.18 & 105.69 & 49.75 & 37.23 & 19.30 \\
\hline 17 & $\ldots-++$ & 1 & 2 & 2.52 & 77.98 & 81.36 & 71.81 & 15.10 \\
\hline 18 & $+\ldots-+-$ & 1 & 2 & 2.25 & 76.00 & 84.95 & 66.95 & 16.78 \\
\hline 19 & -+--+- & 2 & 1 & 2.50 & 67.29 & 88.78 & 69.09 & 18.75 \\
\hline 20 & $++\ldots++$ & 2 & 2 & 3.70 & 69.09 & 91.50 & 68.97 & 22.65 \\
\hline 21 & --+-+- & 2 & 2 & 2.27 & 67.31 & 84.68 & 68.80 & 14.85 \\
\hline 22 & +-+-++ & 1 & 1 & 2.05 & 79.77 & 81.58 & 70.23 & 15.11 \\
\hline 23 & -++-++ & 2 & 1 & 2.33 & 77.84 & 82.47 & 65.95 & 17.97 \\
\hline 24 & +++-+- & 1 & 0 & 1.50 & 86.82 & 72.48 & 55.40 & 19.57 \\
\hline 25 & $\cdots++-$ & 2 & 0 & 1.57 & 76.47 & 81.81 & 57.93 & 18.99 \\
\hline 26 & $+\ldots+++$ & 2 & 0 & 1.85 & 110.49 & 50.93 & 48.93 & 19.86 \\
\hline 27 & -+-+++ & 1 & 0 & 2.97 & 108.60 & 56.01 & 39.21 & 25.20 \\
\hline 28 & ++-++- & 1 & 0 & 1.72 & 121.88 & 39.05 & 42.17 & 20.12 \\
\hline 29 & --++++ & 1 & 0 & 1.58 & 102.95 & 51.69 & 55.30 & 15.42 \\
\hline 30 & +-+++- & 1 & 1 & 1.37 & 129.61 & 36.53 & 39.54 & 15.28 \\
\hline 31 & -++++- & 1 & 0 & 1.93 & 100.68 & 49.74 & 51.59 & 24.51 \\
\hline 32 & ++++++ & 1 & 1 & 1.75 & 121.94 & 47.16 & 30.04 & 17.21 \\
\hline 33 & 000000 & 2 & 1 & 2.67 & 79.18 & 79.39 & 63.05 & 19.26 \\
\hline 34 & 000000 & 2 & 2 & 2.67 & 79.26 & 79.41 & 60.55 & 19.57 \\
\hline 35 & 000000 & 2 & 1 & 2.60 & 84.36 & 78.41 & 56.53 & 17.87 \\
\hline 36 & 000000 & 1 & 1 & 2.98 & 86.66 & 74.24 & 55.20 & 15.06 \\
\hline 37 & 000000 & 1 & 0 & 2.50 & 95.95 & 65.62 & 53.07 & 17.91 \\
\hline 38 & 000000 & 1 & 1 & 2.55 & 95.41 & 67.17 & 53.71 & 18.37 \\
\hline
\end{tabular}

${ }^{a}$ Levels of independent variables shown as Low $(-)$, Medium $(0)$, High $(+)$ are given in the order: $\mathrm{Al}(\mathrm{OH})_{4}, \mathrm{PO}_{4}, \mathrm{SO}_{4}, \mathrm{OH}$, EDTA/HEDTA, NTA.

${ }^{b}$ Bump and Froth defined as $0=$ none, 1 = moderate, 2 = severe, 3 = uncontrollable; additional detail for Froth defined in text. 
Table 5. Concentrations of Metals by Inductively Coupled Plasma Spectroscopy in Washed Crystals (mg/g).

\begin{tabular}{|c|c|c|c|c|}
\hline Test & Al & $\mathrm{Cr}$ & $\mathrm{Na}$ & $\mathbf{P}$ \\
\hline 1 & 0.185 & 0.039 & 280 & 0.04 \\
\hline 2 & 1.100 & 0.044 & 245 & 0.09 \\
\hline 3 & 0.145 & 0.034 & 250 & 17.2 \\
\hline 4 & 0.480 & 0.031 & 275 & 19.5 \\
\hline 5 & 0.355 & 0.055 & 300 & 0.09 \\
\hline 6 & 1.400 & 0.041 & 305 & 0.06 \\
\hline 7 & 0.169 & 0.044 & 279 & 16.5 \\
\hline 8 & 0.370 & 0.027 & 255 & 14.0 \\
\hline 9 & 0.210 & 0.020 & 315 & 0.03 \\
\hline 10 & 0.225 & 0.008 & 255 & 0.05 \\
\hline 11 & 0.060 & 0.017 & 275 & 21.8 \\
\hline 12 & 0.080 & 0.008 & 275 & 18.8 \\
\hline 13 & 0.435 & 0.017 & 265 & 0.03 \\
\hline 14 & 0.115 & 0.014 & 285 & 0.06 \\
\hline 15 & 0.048 & 0.026 & 270 & 22.5 \\
\hline 16 & 0.150 & 0.020 & 265 & 18.0 \\
\hline 17 & 0.245 & 0.038 & 285 & 0.04 \\
\hline 18 & 0.850 & 0.039 & 280 & 0.06 \\
\hline 19 & 0.160 & 0.046 & 290 & 16.2 \\
\hline 20 & 1.200 & 0.055 & 265 & 19.0 \\
\hline 21 & 0.115 & 0.034 & 290 & 0.05 \\
\hline 22 & 0.440 & 0.020 & 285 & 0.03 \\
\hline 23 & 0.155 & 0.050 & 290 & 16.8 \\
\hline 24 & 0.450 & 0.050 & 280 & 19.5 \\
\hline 25 & 0.500 & 0.047 & 275 & 0.12 \\
\hline 26 & 0.650 & 0.017 & 265 & 0.07 \\
\hline 27 & 0.220 & 0.027 & 270 & 27.2 \\
\hline 28 & 0.200 & 0.008 & 275 & 26.2 \\
\hline 29 & 0.070 & 0.012 & 305 & 0.02 \\
\hline 30 & 0.070 & 0.011 & 275 & 0.04 \\
\hline 31 & 0.065 & 0.013 & 255 & 30.0 \\
\hline 32 & 0.055 & 0.018 & 320 & 26.5 \\
\hline 33 & 0.700 & 0.043 & 270 & 5.8 \\
\hline 34 & 0.950 & 0.049 & 295 & 8.8 \\
\hline 35 & 0.500 & 0.031 & 260 & 9.8 \\
\hline 36 & 0.550 & 0.040 & 280 & 3.6 \\
\hline 37 & 0.500 & 0.028 & 305 & 1.8 \\
\hline 38 & 0.325 & 0.021 & 280 & 2.1 \\
\hline
\end{tabular}

Bump: Bumping occurs in the slurry under evaporation when vapor bubbles within the slurry grow so large that they throw slurry into the vapor space when they break the surface, which can lead to contamination of the condensate. There is no quantitative measurement of the extent of bumping, so slurries were assigned the following values based on qualitative comparison to one another:

$0=$ no bumping observed

$1=$ moderate bumping

$2=$ severe bumping

$3=$ uncontrollable bumping resulting in slurry carryover into the condensate 
None of the slurries exhibited uncontrollable (level 3) bumping.

Froth: Frothing occurs in the slurry under evaporation when the vapor bubbles have trouble disengaging from the liquid phase, so a bed of fluid-lined vapor bubbles forms on top of the slurry. The bed is called a "froth" if the bubbles are unstable and break readily into vapor and liquid phases when conditions are changed (e.g., when the vacuum is released), or it is called a "foam" if the bed is stable (e.g., whipped egg whites). Foaming was not observed in any of the tests. The tendency to froth was assigned a numerical value based on the level of froth maintained during evaporation:

$0=$ no froth

$1=$ froth maintained at bed height not exceeding approximately $2 \mathrm{~cm}$

$2=$ bed height exceeds $2 \mathrm{~cm}$ but does not extend into condenser

$3=$ froth enters condenser and contaminates condensate

None of the slurries exhibited frothing at level 3. Note that, in some cases, frothing could be alleviated by changing the stirring rate in the slurry.

Filtrate: The total weight of slurry was measured at the end of each boildown by weighing the boildown pot containing the slurry. Theoretically, the weight of slurry should be nearly constant for all tests. The actual total slurry weights ranged from $159 \mathrm{~g}$ to $175 \mathrm{~g}$. Similarly, the weight of slurry actually delivered to the filter, which should be relatively constant, was measured by weighing the boildown pot before and after transferring the slurry to the filter. The actual weight of slurry delivered to the filter ranged from $150 \mathrm{~g}$ to $172 \mathrm{~g}$. The weight of filtrate (liquid phase that passed through the filter) is not expected to be constant but is expected to vary as a result of several factors that might influence the efficiency of the solid/liquid separation. The weight of filtrate was measured by weighing the receiving flask before and after the filtration. Filtrate weights varied from $67 \mathrm{~g}$ to $130 \mathrm{~g}$. To a first approximation, the efficiency of solid/liquid separation increases as the filtrate weight increases.

Filtration time: The slurry resulting from each boildown was poured into a heated $\left(60^{\circ} \mathrm{C}\right)$ vacuum filter apparatus with a medium-mesh glass frit filter. A timer was started when the vacuum was applied to the filter. The timer was stopped when the filtrate production rate slowed to less than $1 \mathrm{drop} / \mathrm{sec}$. The elapsed time was recorded in minutes. To a first approximation, the effectiveness of the solid/liquid separation increases as the filtration time decreases. None of the slurries in the entire test matrix led to excessive filtration times or filter plugging.

Unwashed crystals: The weight of the filter cake after the initial filtration (unwashed crystals) was not measured directly but was calculated from the difference between the weight of the slurry delivered to the filter and the weight of the filtrate. Using this weight and the concentration of sodium in the washed crystals, the process "\% Yield," or sodium recovery, can be calculated.

Washed crystals: The weight of filter cake remaining after washing with saturated brine was measured directly by collecting the washed crystals in a sample jar. 
Percent water: Two samples of the washed crystals from the sample jar were analyzed for $\% \mathrm{H}_{2} \mathrm{O}$ by oven drying. The average of the two measurements is shown in Table 4 . If all of the product salts were anhydrous, the $\% \mathrm{H}_{2} \mathrm{O}$ determination would provide a direct means of measuring the effectiveness of the solid/liquid separation, as all of the water in the washed crystals would be attributable to retained liquid phase. However, some of the solid phases include waters of hydration, especially $\mathrm{Na}_{3} \mathrm{PO}_{4} \cdot 12 \mathrm{H}_{2} \mathrm{O} \cdot 0.25 \mathrm{NaOH}$, so a direct correlation is not possible. To a first approximation, however, increasing $\% \mathrm{H}_{2} \mathrm{O}$ indicates decreasing solid/liquid separation effectiveness.

Elemental analysis: Small aliquots of the washed crystals were dissolved in dilute nitric acid and analyzed by ICP for concentrations of $\mathrm{Al}, \mathrm{Cr}, \mathrm{Na}$, and $\mathrm{P}$. Results are shown separately in Table 5.

\section{STATISTICAL ANALYSIS}

Results of the statistical analysis of the data in Table 4 and the Cr results from Table 5 are discussed in a separate report (PNNL-17380). A model, or equation, was developed to fit each response. Results are summarized here along with an empirical evaluation of what the results mean in terms of the feed envelope.

\subsection{FILTRATION TIME}

The model that best fits the responses for filtration time is shown in Equation 1, where the values for the independent variables are the assigned levels $-1,0,+1$, not the molar concentrations. [The $-1,0,+1$ values are used for all of the model equations in this report and in the statistics report where the equations originally appeared (PNNL-17380)].

$$
\text { Filt.Time }=\exp \left[\begin{array}{l}
0.7162+0.0421 \cdot P O_{4}-0.1130 \cdot S O_{4}-0.1976 \cdot O H+0.0663 \cdot E D T A \\
+0.0223 \cdot N T A-0.0678 \cdot P O_{4} \cdot S O_{4}+0.0714 \cdot O H \cdot E D T A+0.0731 \cdot E D T A \cdot N T A
\end{array}\right]
$$

For test 1, e.g., with all variables set to their low (-1) values, Equation 1 becomes:

$$
\text { FiltTime }=\exp \left[\begin{array}{l}
0.7162+0.0421 \cdot(-1)-0.1130 \cdot(-1)-0.1976 \cdot(-1)+0.0663 \cdot(-1) \\
+0.0223 \cdot(-1)-0.0678 \cdot(-1) \cdot(-1)+0.0714 \cdot(-1) \cdot(-1)+0.0731 \cdot(-1) \cdot(-1)
\end{array}\right]
$$

Filt.Time $=2.65 \mathrm{~min}$ (compared to the observed $2.62 \mathrm{~min}$ shown in Table 4$)$.

The single-parameter terms in the equation indicate that the filtration time tends to decrease with increasing concentrations of $\mathrm{OH}$ and $\mathrm{SO}_{4}$ and decreasing concentrations of $\mathrm{PO}_{4}$, HEDTA/EDTA, and NTA. (The combined variable EDTA/HEDTA is shown in the equations as EDTA for the sake of brevity.) The interaction terms (those with two variables) modify the effects of the single-parameter terms. So, for example, the decrease in filtration time with increasing $\mathrm{OH}$ concentration is more pronounced when EDTA is at its lowest level. 
Figure 1 shows the hydroxide single-variable effect on filtration time. The general downward trend with increasing $\mathrm{OH}$ reflects the $\mathrm{OH}$ term in Equation 1. It is obvious from Figure 1 that the hydroxide effect alone explains only a small portion of the observed variability, although it has a larger single-parameter effect than any of the other variables.

Figure 1. Hydroxide Effect on Filtration Time.

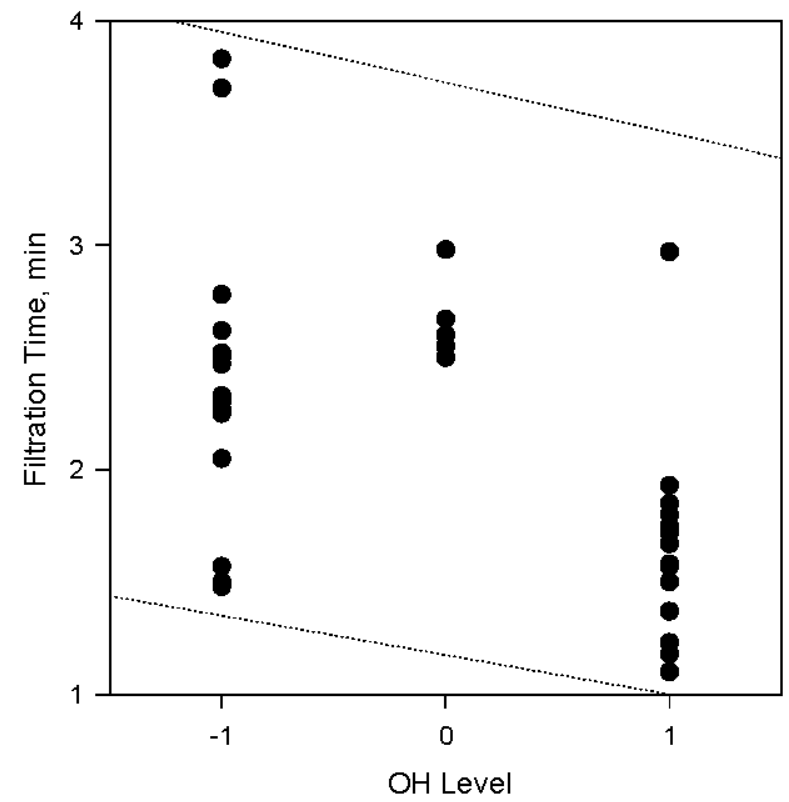

It seems, at first, counterintuitive that increasing $\mathrm{OH}$ would lead to decreased filtration time because increasing $\mathrm{OH}$ ought to correspond to higher viscosity at the boildown end point and thus slower filtration. The explanation is likely tied to the reduction in the dependent variables with increasing $\mathrm{OH}$, i.e., the decreasing concentrations of the major product salts $\mathrm{NaNO}_{3}$ and $\mathrm{Na}_{2} \mathrm{CO}_{3} \cdot \mathrm{H}_{2} \mathrm{O}$.

\subsection{BUMP}

The data in Table 4 were used to develop a model that predicts the probability of experiencing severe bumping (bump response $=2$ ). In equation 2 , the model predicts that the slurry will experience severe bumping if the probability $\left(\mathrm{P}_{\text {Bump }}\right)$ exceeds 0.5 .

$$
P_{\text {Bump }}=\frac{\exp \left[\beta_{0}+\beta_{2} \cdot P O_{4}+\beta_{3} \cdot S O_{4}+\beta_{4} \cdot O H\right]}{1+\exp \left[\beta_{0}+\beta_{2} \cdot P O_{4}+\beta_{3} \cdot S O_{4}+\beta_{4} \cdot O H\right]}
$$

with

$$
\begin{aligned}
& \beta_{0}=-3.0494 \\
& \beta_{2}=-1.7596 \\
& \beta_{3}=-1.4686 \\
& \beta_{4}=-2.5611
\end{aligned}
$$


The model predicts that decreasing levels of $\mathrm{PO}_{4}, \mathrm{SO}_{4}$, and $\mathrm{OH}$ all lead to increased probability of severe bumping. However, within the matrix tested there are only four combinations that lead to $\mathrm{P}_{\text {Bump }}>0.5$, those that contain low (-1) levels of all three variables, namely tests $1,2,17$, and 18.

\subsection{CHROMATE}

Chromate $[\mathrm{Cr}(\mathrm{VI})]$ ion is expected to remain in the liquid phase throughout the fractional crystallization process, much like cesium. (The simulated waste feed solutions for the factorial design test did not include cesium.) Therefore, any chromate present in the washed solids would be a direct indication of contamination of the crystals by residual liquid.

In the original test plan (7S110-DLH-07-122), chromate analysis of the washed crystals was planned using a colorimetric test kit. Test results showed that the colorimetric test was subject to a number of interferences, including nitrite ion. Statistical analysis of the results was originally performed with the flawed colorimetric analytical data. It was later determined by the customer that the samples should be analyzed for chromium (and other metals) by ICP analysis. The statistical analysis was then repeated using the more-accurate ICP data shown in Table 5. The resulting model is shown in Equation 3.

$$
C r(V I) I C P=\exp \left[\begin{array}{l}
\beta_{0}+\beta_{1} \cdot A l+\beta_{3} \cdot S O_{4}+\beta_{4} \cdot O H+\beta_{5} \cdot E D T A \\
+\beta_{14} \cdot A l \cdot O H+\beta_{35} \cdot S O_{4} \cdot E D T A
\end{array}\right]
$$

where

$$
\begin{aligned}
& \beta_{0}=-3.6033 \\
& \beta_{1}=-0.1955 \\
& \beta_{3}=-0.0242 \\
& \beta_{4}=-0.4147 \\
& \beta_{5}=0.0594 \\
& \beta_{14}=-0.1058 \\
& \beta_{35}=-0.1219
\end{aligned}
$$

Due to the strong interaction terms, it is difficult to visualize the effects of the individual variables on the $\mathrm{Cr}(\mathrm{VI})$ response in Equation 3. Table 6 shows the $\mathrm{Cr}$ (VI) concentration at all 16 of the possible high/low combinations of the relevant variables, arranged by increasing $\mathrm{Cr}(\mathrm{VI})$ concentration, as calculated from Equation 3.

Start with the all-low combination at $\mathrm{Cr}=0.039$. Increasing EDTA/HEDTA only (bottom row) causes a large increase in $\mathrm{Cr}$. Increasing $\mathrm{SO}_{4}$ only also causes a large increase (next-to-bottom row). Increasing $\mathrm{Al}(\mathrm{OH})_{4}$ only causes a slight decrease $(\mathrm{Cr}=0.032)$. Increasing $\mathrm{OH}$ only causes a large decrease $(\mathrm{Cr}=0.021)$.

The large increases in $\mathrm{Cr}$ with increasing EDTA/HEDTA and $\mathrm{SO}_{4}$ are nullified when $\mathrm{OH}$ is also increased. Note that the lowest eight $\mathrm{Cr}$ values in the table all have high $\mathrm{OH}$.

For more information on the chromate results, see Section 3.5. 
Table 6. Calculated Cr(VI) Concentration at Different Variable Settings [sorted by calculated $\mathrm{Cr}$ (VI) concentration].

\begin{tabular}{|c|c|c|c|c|}
\hline $\mathbf{A l}(\mathbf{O H})_{\mathbf{4}}$ & $\mathbf{S O}_{\mathbf{4}}$ & $\mathbf{O H}$ & EDTA/HEDTA & $\begin{array}{c}\text { Calculated } \\
\mathbf{C r}(\mathbf{V I}), \mathbf{m g} / \mathbf{g}\end{array}$ \\
\hline+1 & -1 & +1 & -1 & 0.011 \\
\hline+1 & +1 & +1 & +1 & 0.012 \\
\hline+1 & +1 & +1 & -1 & 0.014 \\
\hline+1 & -1 & +1 & +1 & 0.016 \\
\hline-1 & -1 & +1 & -1 & 0.021 \\
\hline-1 & +1 & +1 & +1 & 0.023 \\
\hline-1 & +1 & +1 & -1 & 0.026 \\
\hline-1 & -1 & +1 & +1 & 0.030 \\
\hline+1 & -1 & -1 & -1 & 0.032 \\
\hline+1 & +1 & -1 & +1 & 0.035 \\
\hline-1 & -1 & -1 & -1 & 0.039 \\
\hline+1 & +1 & -1 & -1 & 0.039 \\
\hline-1 & +1 & -1 & +1 & 0.042 \\
\hline+1 & -1 & -1 & +1 & 0.046 \\
\hline-1 & +1 & -1 & -1 & 0.047 \\
\hline-1 & -1 & -1 & +1 & 0.056 \\
\hline
\end{tabular}

\subsection{UNDILUTED FILTRATE}

Statistical analysis of the response data for weight of filtrate resulted in Equation 4 (where "Und.Filtrate" stands for undiluted filtrate, which is the same as Filtrate in Table 4).

$$
\text { Und.Filtrate }=\exp \left[4.5182+0.0787 \cdot \mathrm{Al}+0.0397 \cdot \mathrm{SO}_{4}+0.1603 \cdot \mathrm{OH}\right]
$$

Equation 4 suggests that the weight of filtrate increases with increasing concentrations of $\mathrm{Al}(\mathrm{OH})_{4}, \mathrm{SO}_{4}$, and $\mathrm{OH}$ and is independent of $\mathrm{PO}_{4}$, EDTA/HEDTA, and NTA. Increasing weight of filtrate, at relatively constant slurry weight, corresponds to decreasing weight of crystals, and hence lower sodium recovery (lower \%Yield). In other words, increasing $\mathrm{Al}(\mathrm{OH})_{4}, \mathrm{SO}_{4}$ and $\mathrm{OH}$ corresponds to decreasing $\mathrm{NaNO}_{3}$ and $\mathrm{Na}_{2} \mathrm{CO}_{3} \cdot \mathrm{H}_{2} \mathrm{O}$, resulting in decreasing yield. It is surprising that the equation lacks a term for $\mathrm{PO}_{4}$.

\subsection{WEIGHT PERCENT WATER}

Equation 5 shows the model that best fits the response data for $\% \mathrm{H}_{2} \mathrm{O}$. Not surprisingly, $\mathrm{PO}_{4}$ is the dominant variable. The $\mathrm{Al}-\mathrm{OH}$ interaction term is interesting. When $\mathrm{Al}$ is high, the $\mathrm{OH}$ and $\mathrm{Al}-\mathrm{OH}$ terms effectively cancel each other out regardless of the $\mathrm{OH}$ level. When $\mathrm{Al}$ is low, the $\% \mathrm{H}_{2} \mathrm{O}$ increases with increasing $\mathrm{OH}$ and decreases with decreasing $\mathrm{OH}$.

$$
\mathrm{H}_{2} \mathrm{OW} \%=18.6334+0.0104 \cdot \mathrm{Al}+2.0284 \cdot \mathrm{PO}_{4}-0.8315 \cdot \mathrm{SO}_{4}+0.8956 \cdot \mathrm{OH}-0.9050 \cdot \mathrm{Al} \cdot \mathrm{OH}
$$

In theory, increasing $\% \mathrm{H}_{2} \mathrm{O}$ corresponds to increasing liquid contamination, which in turn means increasing $\mathrm{Cr}(\mathrm{VI})$ concentration in the washed solids. The data, however, show no such correlation. Figure 2 shows a plot of $\% \mathrm{H}_{2} \mathrm{O}$ vs. $\mathrm{Cr}$ analytical results for the washed solids with one set of data points for the low- $\mathrm{PO}_{4}$ runs and another set of points for the high- $\mathrm{PO}_{4}$ runs. The 
$\mathrm{PO}_{4}$ effect on $\% \mathrm{H}_{2} \mathrm{O}$ is clearly evident in the figure. Just as clearly, there is no correlation between $\% \mathrm{H}_{2} \mathrm{O}$ and $\mathrm{Cr}$ for either set of data points, contrary to theory.

Figure 2. Lack of Correlation Between $\% \mathrm{H}_{2} \mathrm{O}$ and $\mathrm{Cr}$ in Washed Solids.

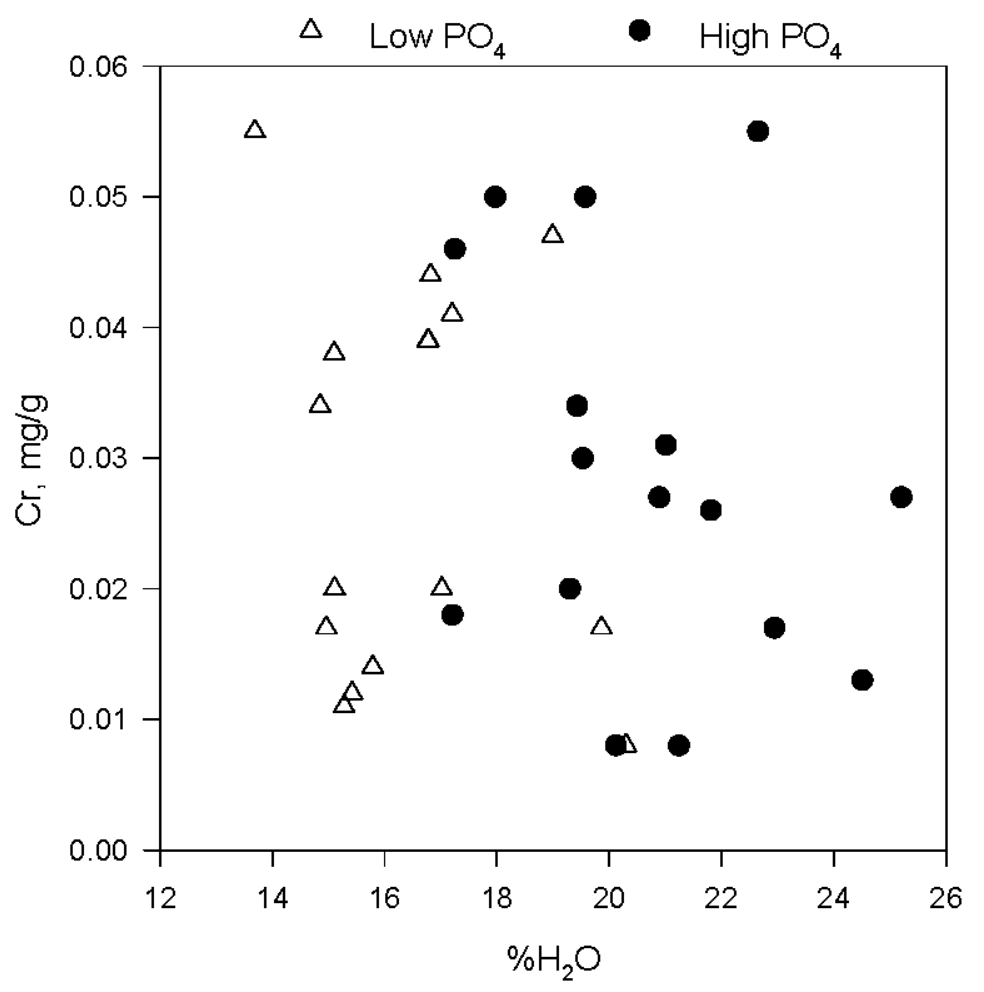

\subsection{WASHED CRYSTALS}

The model used to fit the response data for the weight of washed crystals (Equation 6) includes terms for every variable except EDTA/HEDTA. The relationships are straightforward - increase in any variable corresponds to a decrease in the weight of washed crystals.

$$
\begin{aligned}
\text { WashedCrystals }= & 55.0440-3.3141 \cdot A l-4.1310 \cdot \mathrm{PO}_{4}-1.9873 \cdot \mathrm{SO}_{4}-10.2503 \cdot \mathrm{OH} \\
& -0.3496 \cdot \mathrm{NTA}-2.0933 \cdot \mathrm{Al} \cdot \mathrm{OH}-4.7996 \cdot \mathrm{OH} \cdot \mathrm{NTA}
\end{aligned}
$$

The reason is fairly transparent. An increase in the level of any variable corresponds to a decrease in the levels of the major product salts, i.e., $\mathrm{NaNO}_{3}$ and $\mathrm{Na}_{2} \mathrm{CO}_{3} \cdot \mathrm{H}_{2} \mathrm{O}$. This is obvious from a plot of the weight of washed crystals as a function of, e.g., the molarity of $\mathrm{NaNO}_{3}$ in the feed solution (Figure 3). The plot would look the same, qualitatively, if $\mathrm{Na}_{2} \mathrm{CO}_{3} \cdot \mathrm{H}_{2} \mathrm{O}$ were substituted for $\mathrm{NaNO}_{3}$. 
Figure 3. Correlation Between Mass of Washed Crystals and Nitrate Molarity.

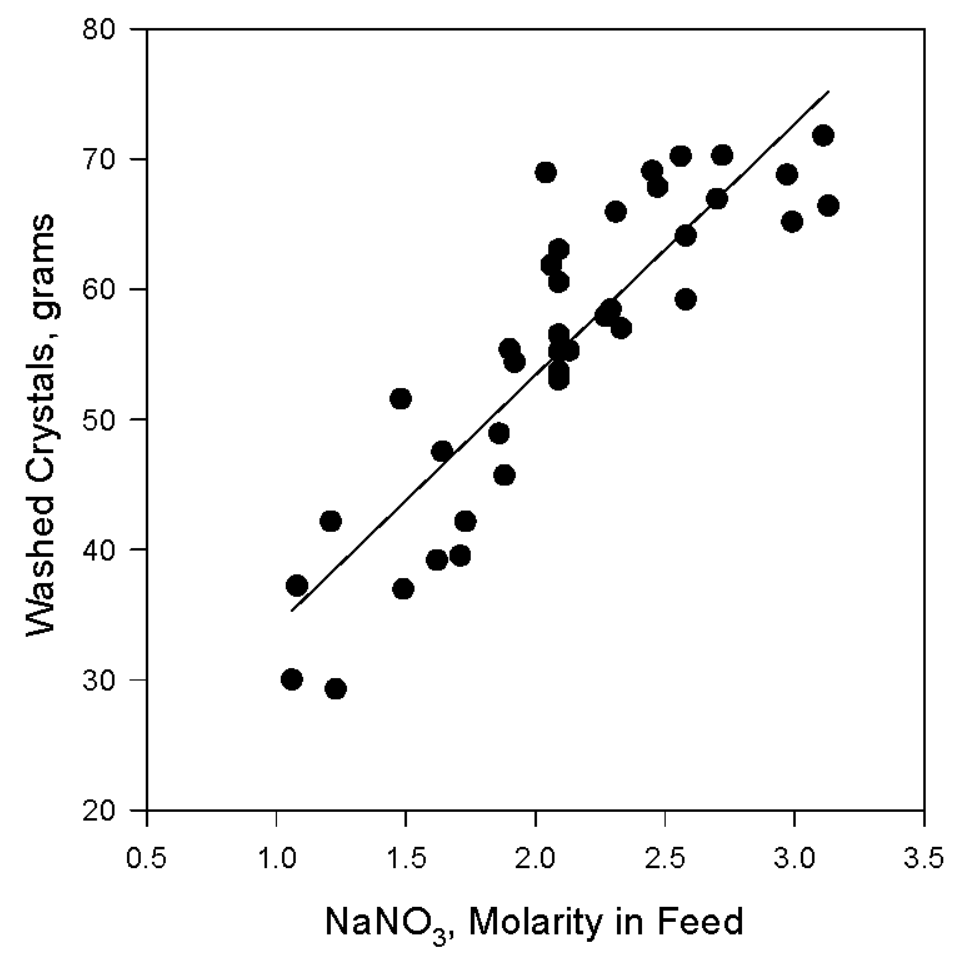

\subsection{FROTH}

No statistical model was found that would adequately fit the response data for frothing.

\section{DECONTAMINATION FACTORS AND SODIUM RECOVERY}

The primary indicator of the separation effectiveness of the fractional crystallization process is the decontamination factor (DF), which is defined as the analyte:Na ratio in the feed divided by the analyte: Na ratio in the product (washed crystals). The primary indicator of the process efficiency is the sodium recovery, or \% Yield, which is defined as the mass of $\mathrm{Na}$ in the unwashed crystals relative to the mass of $\mathrm{Na}$ in the feed solution, expressed as a percentage. (Any Na lost during the wash step is recycled back into the feed.)

These two "responses" were not subjected to statistical modeling because the data were not available at the time of the modeling. Calculation of DF and \%Yield requires analysis of the product crystals by ICP analysis, which was performed only later in the program.

\subsection{DECONTAMINATION FACTORS}

Typically, the analyte used to determine $\mathrm{DF}$ would be a radionuclide, e.g., ${ }^{137} \mathrm{Cs}\left(\mathrm{DF}_{\mathrm{Cs}}\right)$. The feed solutions for the current study did not contain cesium, radioactive or nonradioactive, but other analytes can be used to calculate the DF providing that the analyte remains in the liquid phase throughout the process. Such analytes typically include nitrite, chloride, potassium, and chromate. 
Values for $\mathrm{DF}_{\mathrm{Cr}}, \mathrm{DF}_{\mathrm{Al}}$, and $\mathrm{DF}_{\mathrm{PO} 4}$ (for Low- $\mathrm{PO}_{4}$ runs only) were calculated from the ICP results in Table 5 and the feed molarities in Table 3. The results are shown in Table 7 along with the $\%$ Yield results discussed in Section 5.2.

Table 7. Decontamination Factors and \%Yield.

\begin{tabular}{|c|c|c|c|c|c|}
\hline Test & Levels & $\mathrm{DF}_{\mathrm{Al}}$ & $\mathrm{DF}_{\mathrm{Cr}}$ & $\mathrm{DF}_{\mathrm{PO4}}$ & $\%$ Yield \\
\hline 1 & $-\ldots-\cdots$ & 81 & 47 & 60 & 60.0 \\
\hline 2 & +----+ & 39 & 31 & 27 & 59.9 \\
\hline 3 & -+---+ & 91 & 38 & (*) & 57.3 \\
\hline 4 & ++---- & 99 & 38 & (*) & 57.7 \\
\hline 5 & --+--+ & 45 & 34 & 33 & 74.5 \\
\hline 6 & +-+--- & 38 & 40 & 46 & 68.1 \\
\hline 7 & -++--- & 88 & 31 & (*) & 58.6 \\
\hline 8 & $+++-\ldots+$ & 119 & 38 & (*) & 44.6 \\
\hline 9 & ---+-+ & 81 & 75 & 94 & 58.8 \\
\hline 10 & +--+-- & 199 & 124 & 53 & 30.5 \\
\hline 11 & -+-+-- & 243 & 56 & (*) & 46.8 \\
\hline 12 & ++-+-+ & 595 & 87 & (*) & 27.9 \\
\hline 13 & +-+--- & 107 & 83 & 92 & 47.7 \\
\hline 14 & +-++-+ & 435 & 76 & 47 & 31.6 \\
\hline 15 & -+++-+ & 302 & 33 & (*) & 32.8 \\
\hline 16 & ++++-- & 306 & 31 & (*) & 36.4 \\
\hline 17 & ----++ & 62 & 49 & 68 & 64.1 \\
\hline 18 & +---+- & 58 & 40 & 46 & 65.7 \\
\hline 19 & -+--+- & 96 & 32 & (*) & 71.1 \\
\hline 20 & ++--++ & 38 & 20 & (*) & 67.0 \\
\hline 21 & --+-+- & 135 & 52 & 54 & 67.8 \\
\hline 22 & +-+-++ & 113 & 77 & 107 & 64.2 \\
\hline 23 & -++-++ & 99 & 28 & (*) & 66.1 \\
\hline 24 & +++-+- & 108 & 22 & (*) & 56.1 \\
\hline 25 & ---++- & 30 & 28 & 21 & 62.1 \\
\hline 26 & +--+++ & 71 & 60 & 34 & 37.3 \\
\hline 27 & -+-+++ & 65 & 33 & (*) & 41.8 \\
\hline 28 & ++-++- & 238 & 86 & (*) & 29.7 \\
\hline 29 & --++++ & 234 & 117 & 143 & 43.6 \\
\hline 30 & +-+++- & 689 & 93 & 74 & 27.8 \\
\hline 31 & -++++- & 208 & 60 & (*) & 35.0 \\
\hline 32 & ++++++ & 1,008 & 40 & (*) & 41.7 \\
\hline 33 & 000000 & 44 & 27 & (*) & 59.2 \\
\hline 34 & 000000 & 35 & 26 & (*) & 64.7 \\
\hline 35 & 000000 & 59 & 36 & (*) & 56.3 \\
\hline 36 & 000000 & 58 & 31 & (*) & 57.4 \\
\hline 37 & 000000 & 69 & 48 & (*) & 55.3 \\
\hline 38 & 000000 & 98 & 58 & (*) & 52.0 \\
\hline
\end{tabular}

${ }^{*} \mathrm{DF}_{\mathrm{PO} 4}$ calculated for Low- $\mathrm{PO}_{4}$ runs only because the washed crystals clearly contained sodium phosphate solids in all Medium- $\mathrm{PO}_{4}$ and High- $\mathrm{PO}_{4}$ runs.

If the analytical results are accurate, and if the analytes in question truly did remain in the liquid phase throughout the process, then each of the analytes should give the same DF for each run, i.e., $\mathrm{DF}_{\mathrm{Al}}=\mathrm{DF}_{\mathrm{Cr}}=\mathrm{DF}_{\mathrm{PO} 4}$ for any given run. Graphical interpretation of the DF data shows at least some correlation between $\mathrm{DF}_{\mathrm{Cr}}$ and $\mathrm{DF}_{\mathrm{PO} 4}$ (Figure 4). No such correlation exists between 
$\mathrm{DF}_{\mathrm{Al}}$ and either of the other DFs. Furthermore, several of the $\mathrm{DF}_{\mathrm{Al}}$ values are unrealistically high $(>300)$, suggesting some kind of analytical anomaly for aluminum that remains unresolved.

Figure 4. Correlation Between $\mathrm{DF}_{\mathrm{Cr}}$ and $\mathrm{DF}_{\mathrm{PO} 4}$.

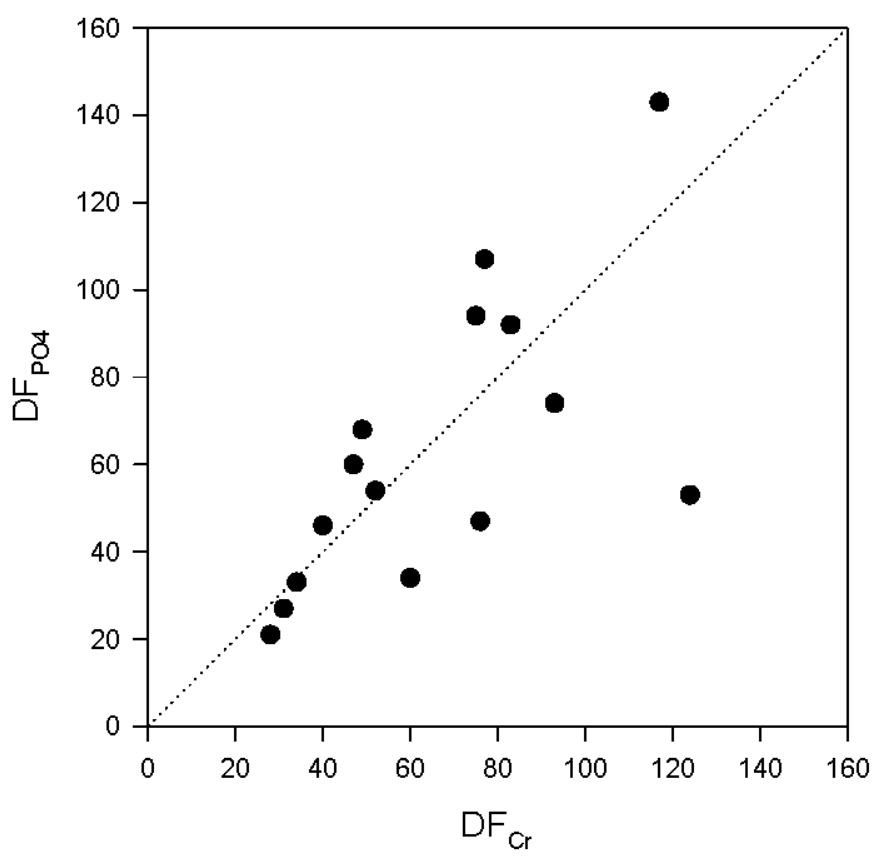

The DF values in Table 7 would accurately reflect the expected $\mathrm{DF}_{\mathrm{Cs}}$ only if the aluminate, chromate, and phosphate remained in the liquid phase. The data suggest, however, that precipitation does occur for each of the three analytes in some of the runs, which leads to DF values that are lower than $\mathrm{DF}_{\mathrm{Cs}}$ would be if $\mathrm{Cs}$ had been present in the feed. In the case of chromate, the statistical modeling of the Cr(VI) response data (Section 4.3) showed that the $\mathrm{Cr}$ (VI) concentration in the washed crystals increases with increasing EDTA/HEDTA and sulfate concentrations, suggesting that those components cause precipitation or co-precipitation of $\mathrm{Cr}(\mathrm{VI})$. For example, it is possible that the chromate ion $\left(\mathrm{CrO}_{4}{ }^{2-}\right)$ can substitute for sulfate ion in the burkeite crystal lattice, $\mathrm{Na}_{6} \mathrm{CO}_{3}\left(\mathrm{SO}_{4}\right)_{2}$, as the two ions have the same charge and very nearly the same size.

\subsection{SODIUM RECOVERY}

The calculated \%Yield for each run is shown in Table 7. To calculate the \%Yield, the concentration of $\mathrm{Na}$ in the washed crystals in $\mathrm{mg} / \mathrm{g}$ (Table 5) is multiplied by the weight of unwashed crystals in $\mathrm{g}$ (Table 4) and divided by the weight of $\mathrm{Na}$ in the feed solution, which was constant at $36.2 \mathrm{~g}$ for every run. The concentration is based on the washed crystals because they represent the final product of the separation process. The total weight is based on the unwashed crystals because any amount of $\mathrm{Na}$ washed out of the filter cake is returned to the evaporator in the continuous process, so the total yield is based on the amount of pre-washed filter cake.

The Na concentration in the washed crystals (Table 5) showed little variation, so a strong correlation between \% Yield and the mass of unwashed crystals (Figure 5) is not surprising. 


\section{Figure 5. Correlation Between Percent Yield and the} Mass of Unwashed Crystals.

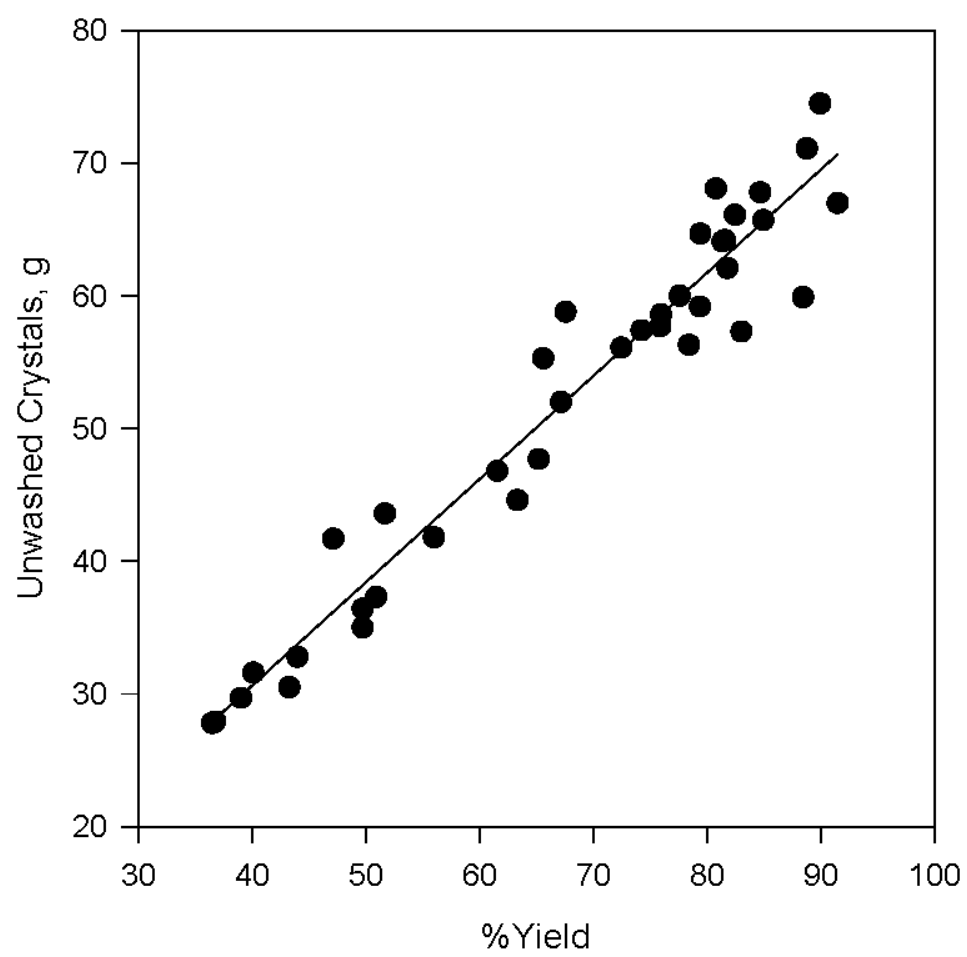

The weight of unwashed crystals is a calculated value found by subtracting the weight of filtrate from the [nearly constant] weight of slurry delivered to the filter. Therefore, there is an inverse relationship between the weight of unwashed crystals and the weight of filtrate, the latter having been modeled by statistical analysis (Section 4.4). The modeling showed that weight of filtrate increased with increasing concentrations of $\mathrm{Al}(\mathrm{OH})_{4}, \mathrm{SO}_{4}$, and $\mathrm{OH}$. Therefore, the modeling suggests the expected result that the \%Yield increases as the concentrations of $\mathrm{NaNO}_{3}$ and $\mathrm{Na}_{2} \mathrm{CO}_{3}$ increase in the feed solution.

\section{ENVELOPE LIMITS}

The rationale for selecting the envelope limit concentrations in Table 1 is presented for each analyte.

\subsection{HYDROXIDE}

The $\mathrm{OH}$ concentrations used in the statistical design test were [normalized to $5 \mathrm{M} \mathrm{Na}$ ]:

a. $\operatorname{Low}(-1)=0.49 \mathrm{M}$

b. Medium $(0)=1.02 \mathrm{M}$

c. High $(+1)=1.55 \mathrm{M}$ 
Statistical modeling results (Section 4) show that increasing $\mathrm{OH}$ concentration had both a positive impact (reduced filtration time, reduced $\mathrm{Cr}$ contamination) and a negative impact (increased $\% \mathrm{H}_{2} \mathrm{O}$, decreased $\%$ Yield) on the process. None of the tests resulted in catastrophic failure of the process.

Previous thermodynamic modeling (RPP-34455) proposed a limit of $2.1 \mathrm{M}$ for the sum of the concentrations of $\mathrm{OH}$ and $\mathrm{Al}(\mathrm{OH})_{4}$, based on their effects on ionic strength (\% Yield) and on prevention of sodium aluminate crystallization. That limit $\left[\mathrm{OH}+\mathrm{Al}(\mathrm{OH})_{4}=2.1 \mathrm{M}\right.$ at $5 \mathrm{M}$ total $\mathrm{Na}$ ] was selected to represent the $\mathrm{OH}$ envelope limit in Table 1.

Eight out of the 38 runs in the half-factorial matrix (runs 10, 12, 14, 16, 26, 28, 30, 32) had $[\mathrm{OH}$ $\left.+\mathrm{Al}(\mathrm{OH})_{4}\right]$ concentration higher than this limit $(1.55+0.75=2.30 \mathrm{M})$. The $\%$ Yield for those eight runs averaged $32.9 \%$, compared to an average of $57.2 \%$ for the remaining 30 runs (see Table 7). These results lend credence to the selection of the $\mathrm{OH}$ limit shown in Table 1.

\subsection{ALUMINATE}

The $\mathrm{Al}(\mathrm{OH})_{4}$ concentrations used in the statistical design test were [normalized to $5 \mathrm{M} \mathrm{Na}$ ]:

a. $\operatorname{Low}(-1)=0.23 \mathrm{M}$.

b. Medium $(0)=0.49 \mathrm{M}$.

c. High $(+1)=0.75 \mathrm{M}$.

Statistical modeling results (Section 4) show that increasing $\mathrm{Al}(\mathrm{OH})_{4}$ concentration had a negative impact on the weight of filtrate and the weight of washed crystals and had a positive impact on $\mathrm{Cr}(\mathrm{VI})$ concentration [increasing $\mathrm{Al}(\mathrm{OH})_{4}$ caused decreasing $\mathrm{Cr}(\mathrm{VI})$ ]. Therefore, short of precipitating sodium aluminate, the only negative impact of increasing $\mathrm{Al}(\mathrm{OH})_{4}$ is its effect on \%Yield. That effect can be calculated from Equation 4 and some basic assumptions, i.e., assuming an average slurry weight of $160 \mathrm{~g}$ and an average $\mathrm{Na}$ concentration in the washed crystals of $280 \mathrm{mg} / \mathrm{g}(28 \% \mathrm{Na})$. The calculated \%Yield for the case where $\mathrm{Al}(\mathrm{OH})_{4}, \mathrm{SO}_{4}$, and $\mathrm{OH}$ are all set to their middle $(0)$ levels would be

$$
\begin{gathered}
\% \mathrm{Yield}_{0 / 0 / 0}=100 *[\text { wt Na in unwashed crystals }] /(36.2 \mathrm{~g} \text { total Na })=\% \text { Yield } \\
\% \mathrm{Yield}_{0 / 0 / 0}=100 * \% \mathrm{Na} / 100 *[\text { wt unwashed crystals }] /(36.2 \mathrm{~g} \text { total } \mathrm{Na})=\% \text { Yield } \\
\% \mathrm{Yield}_{0 / 0 / 0}=100 * 0.28 *[\text { wt slurry }-\mathrm{wt} \text { filtrate }] /(36.2 \mathrm{~g} \text { total Na })=\% \text { Yield } \\
\% \text { Yield }_{0 / 0 / 0}=100 * 0.28 *[160-\exp (4.52)] /(36.2 \mathrm{~g} \text { total Na })=52.7 \%
\end{gathered}
$$

where "wt filtrate" comes from Equation 4 with all parameters at their middle (0) levels. All 38 runs contained $36.2 \mathrm{~g} \mathrm{Na}$ in the feed.

Increasing $\mathrm{Al}(\mathrm{OH})_{4}$ from the middle level to its high level would decrease the \%Yield to

$$
\% \text { Yield }_{1 / 0 / 0}=100 * 0.28 *[160-\exp (4.52+0.08)] /(36.2 \mathrm{~g} \text { total } \mathrm{Na})=46.8 \%
$$


Note that in previous laboratory studies and in thermodynamic modeling, 50\% Yield was considered the minimum acceptable yield for the process. In the current laboratory study, the focus was on maintaining consistency (minimizing extraneous variables), and individual outcomes like \%Yield and DF may have suffered compared to what could be achieved for a particular feed solution under alternative operating conditions. Therefore, numbers like the $\%$ Yield values just calculated are more important for examining trends than for establishing benchmark values. In other words, the finding that the latter scenario above resulted in a \% Yield below $50 \%$ does not mean that the process "failed" for that combination of variables nor that $0.75 \mathrm{M}$ is an unacceptable level for $\mathrm{Al}(\mathrm{OH})_{4}$ concentration in the feed.

Previous thermodynamic modeling proposed a limit of $2.1 \mathrm{M}$ for the sum of the concentrations of $\mathrm{OH}$ and $\mathrm{Al}(\mathrm{OH})_{4}$. Previous laboratory testing (RPP-RPT-35261) showed that feed solution containing up to $1.2 \mathrm{M} \mathrm{Al}(\mathrm{OH})_{4}$ (normalized to $5 \mathrm{M}$ total $\mathrm{Na}$ ) could be evaporated without encountering the problems of high viscosity and slow filtration caused by sodium aluminate crystallization at higher concentration.

The value for the $\mathrm{Al}(\mathrm{OH})_{4}$ limit in Table 1 was set equal to the high $(+1)$ level for the factorial design test. This level did not cause catastrophic failure under any of the possible combinations of the other variables in the study. Prior laboratory testing shows that higher levels of $\mathrm{Al}(\mathrm{OH})_{4}$ can be processed under at least the one combination of other variables used for that study, so the $\mathrm{Al}(\mathrm{OH})_{4}$ limit in Table 1 can likely be exceeded under some scenarios.

\subsection{PHOSPHATE}

The $\mathrm{PO}_{4}$ concentrations used in the statistical design test were [normalized to $5 \mathrm{M} \mathrm{Na}$ ]:
a. Low $(-1)=0.035 \mathrm{M}$
b. Medium $(0)=0.17 \mathrm{M}$
c. High $(+1)=0.30 \mathrm{M}$

Statistical modeling results (Section 4) show that increasing $\mathrm{PO}_{4}$ concentration had a negative impact on filtration time and a positive impact on bumping of the slurry (i.e., less bumping at high $\mathrm{PO}_{4}$ levels). There was no measurable impact on $\mathrm{Cr}(\mathrm{VI})$ concentration in the filter cake or on the weight of filtrate (or \% Yield).

Thermodynamic modeling was not performed for $\mathrm{PO}_{4}$ due to the lack of appropriate thermodynamic data for $\mathrm{PO}_{4}$ salts in the database. Preliminary laboratory tests were done to establish an upper bound for $\mathrm{PO}_{4}$, and showed that $\mathrm{PO}_{4}$ concentrations up to $0.37 \mathrm{M}$ (normalized to $5 \mathrm{M}$ total $\mathrm{Na}$ ) could be processed without encountering the thickened slurry problems seen at higher concentrations (RPP-RPT-35261). The Table 1 value is set equal to the High $(+1)$ value from the current study because it encompasses a broader range of other components, but again, higher values would be possible under some scenarios. 


\subsection{SULFATE}

The $\mathrm{SO}_{4}$ concentrations used in the statistical design test were [normalized to $5 \mathrm{M} \mathrm{Na}$ ]:

a. $\operatorname{Low}(-1)=0.11 \mathrm{M}$

b. Medium $(0)=0.155 \mathrm{M}$

c. High $(+1)=0.20 \mathrm{M}$

Statistical modeling results (Section 4) show that increasing $\mathrm{SO}_{4}$ concentration had a negative impact on the weight of filtrate and washed crystals (i.e., decreased \%Yield), but the effects were relatively small compared to the other variables. It had a positive impact on filtration time and $\% \mathrm{H}_{2} \mathrm{O}$ in the filter cake.

Thermodynamic modeling indicates that there was no upper limit to $\mathrm{SO}_{4}$ concentration other than its solubility limit. Preliminary laboratory tests show that $\mathrm{SO}_{4}$ concentrations up to $0.55 \mathrm{M}$ (the solubility limit of $\mathrm{Na}_{2} \mathrm{SO}_{4}$ in the solution matrix used for that study, normalized to $5 \mathrm{M}$ total $\mathrm{Na}$ ) could be processed without any difficulties being encountered (RPP-RPT-35261).

The High (+1) level of $\mathrm{SO}_{4}$ from the current factorial test encompasses all but three $200 \mathrm{~W}$ Area single-shell tanks, based on BBI data, but the value selected for Table $1(0.30 \mathrm{M})$ encompasses all of the tanks and is well below the saturation limit $(0.55 \mathrm{M})$ processed without difficulty in the preliminary laboratory tests.

\subsection{ETHYLENEDIAMINETETRAACETIC ACID, TETRASODIUM SALT}

The EDTA/HEDTA concentrations used in the statistical design test were (sum of both compounds at 1:1 mole ratio, normalized to $5 \mathrm{M}$ total $\mathrm{Na}$ ):
a. Low $(-1)=0.007 \mathrm{M}$
b. Medium $(0)=0.010 \mathrm{M}$
c. High $(+1)=0.014 \mathrm{M}$

Statistical modeling results (Section 4) show that increasing EDTA/HEDTA concentration had a negative impact on filtration time and on $\mathrm{Cr}(\mathrm{VI})$ concentration in the filter cake. It had no positive impacts. The negative impact on $\mathrm{Cr}(\mathrm{VI})$ concentration was nullified at high $\mathrm{OH}$.

No thermodynamic modeling was done on EDTA/HEDTA, and no BBI data are available. In previous laboratory studies at Georgia Tech (RPP-RPT-34136), EDTA/HEDTA caused extreme frothing problems at $0.028 \mathrm{M}$, twice the level of the High $(+1)$ setting in the current study. Therefore, the upper limit selected for Table 1 is set equal to the High $(+1)$ setting of $0.014 \mathrm{M}$ combined (EDTA + HEDTA), or $0.007 \mathrm{M}$ for each compound. 


\subsection{NITRILOTRIACETIC ACID, TRISODIUM SALT}

The NTA concentrations used in the statistical design test were [normalized to $5 \mathrm{M}$ total Na]:
a. $\operatorname{Low}(-1)=0.0006 \mathrm{M}$
b. Medium $(0)=0.0010 \mathrm{M}$
c. High $(+1)=0.0013 \mathrm{M}$

Statistical modeling results (Section 4) showed that increasing NTA concentration had a negative impact on filtration time and on the weight of washed crystals. It had no positive impacts.

No thermodynamic modeling was done on NTA, and no BBI data are available. In previous laboratory studies at Georgia Tech (RPP-RPT-34136), NTA caused increased filtration time problems at $0.0025 \mathrm{M}$, twice the level of the High $(+1)$ setting in the current study. Therefore, the upper limit selected for Table 1 is set equal to the High $(+1)$ setting of $0.0013 \mathrm{M}$.

\subsection{CARBONATE}

Carbonate was not one of the independent variables tested in the factorial design laboratory study. Thermodynamic modeling suggests that there is no upper limit to its concentration in the feed other than its solubility limit. The value shown in Table $1(2.5 \mathrm{M}$ at $5 \mathrm{M}$ total $\mathrm{Na})$ is the concentration of carbonate in a pure sodium carbonate solution.

\subsection{NITRITE}

Nitrite was not one of the independent variables tested in the factorial design laboratory study. Thermodynamic modeling indicates that increasing $\mathrm{NO}_{2}$ concentration causes loss of yield due to the high-solubility eutectic formed with sodium nitrate. The magnitude of the effect depends on the evaporation temperature and the $\mathrm{OH}$ concentration, varying from about $0.5 \mathrm{M}$ to $2.1 \mathrm{M} \mathrm{NO}_{2}$ at $5 \mathrm{M}$ total $\mathrm{Na}$. The concentration limit shown in Table $1(1.0 \mathrm{M}$ at $5 \mathrm{M} \mathrm{Na})$ is selected as an average conservative value that could be exceeded for specific feed compositions.

\section{REFERENCES}

7S110-DLH-07-122, 2007, "Test Plan for Envelope Limit Factorial Design Test" (interoffice memorandum from D. L. Herting to D. W. Hamilton, July 31), CH2M HILL Hanford Group, Inc., Richland, Washington.

PNNL-17380, 2008, Analysis of Results from the Design Envelope Limit Experiment, Pacific Northwest National Laboratory, Richland, Washington,

RPP-34455, 2007, Hanford Medium/Low Curie Waste Pretreatment Alternatives ProjectSubtask 2.1 and Subtask 2.2, Rev. 0, CH2M HILL Hanford Group, Inc., Richland, Washington. 
RPP-RPT-36854, Rev. 0

RPP-RPT-34136, 2007, Hanford Medium/Low Curie Waste Pretreatment Alternatives ProjectPhase II, Subtask 2.5 and Subtask 2.6, Rev. 0, CH2M HILL Hanford Group, Inc., Richland, Washington.

RPP-RPT-35261, 2007, Fractional Crystallization Laboratory Tests with Simulated Tank Waste, Rev. 0, CH2M HILL Hanford Group, Inc., Richland, Washington. 